\title{
Determination of Apparent Formation Constants of Eu(III) with Humic Substances by Ion Selective Liquid Membrane Electrode
}

\author{
Takayuki Sasaki ${ }^{*}$, Hatsumi Yoshida ${ }^{1}$, Taishi Kobayashi ${ }^{1}$, Ikuji Takagi $^{1}$, Hirotake Moriyama ${ }^{2}$ \\ ${ }^{1}$ Department of Nuclear Engineering, Kyoto University, Kyoto, Japan \\ ${ }^{2}$ Research Reactor Institute, Kyoto University, Osaka, Japan \\ Email: "sasaki@nucleng.kyoto-u.ac.jp
}

Received April 15, 2012; revised May 10, 2012; accepted June 7, 2012

\begin{abstract}
This is the novel measurement of the apparent formation constants of trivalent lanthanide with humic substances by potentiometric titration using an ion selective electrode (ISE) consisting of bis(diphenylphosphoryl)methane as an ionophore. The ISE prepared exhibited a Nernstian response to the $\mathrm{Eu}^{3+}$ concentration in the test solutions in the presence of humic acid and fulvic acid. The effect of the solution conditions, including the $\mathrm{pH}$, initial metal and humic substance concentrations, and ionic strength, on the formation constants was examined. The present formation constants were compared with the reported data using solvent extraction method.
\end{abstract}

Keywords: Apparent Formation Constant; Humic Substance; Eu(III); Ion Selective Electrode; Titration

\section{Introduction}

Naturally occurring humic substances (fulvic and humic acids) exist in colloidal, suspended, and dissolved forms in groundwater. The molecular framework of these substances consists of aromatic rings and hydrocarbon chains. The negatively charged major functional groups-carboxyl and phenol groups-are distributed heterogeneously and coordinate with numerous radionuclides, including those in the trivalent ions of $\mathrm{Am}, \mathrm{Cm}$, and lanthanides $[1,2]$ as radioactive wastes, which arise from the reprocessing of the spent fuel used in nuclear power plants. Thus, understanding the impact of humic substances on the migration behavior of trivalent radionuclides has been essential for safety assessments related to the disposal of such radioactive waste. The migration behavior of the trivalent metal ions is predominantly controlled by the solubility products, along with the sorption onto an artificial barrier and host rock in groundwater. Therefore, there is an intrinsic need for the formation constants of water-soluble organometallic species from the chemical thermodynamics point of view.

The apparent formation constants of metal-humate complexes under a variety of aquatic conditions have been determined using several traditional methods such as solvent extraction [3], spectrophotometry, conductimetry, ion exchange methods such as Schubert's method [46], ultra filtration [7,8], equilibrium dialysis method [9],

${ }^{*}$ Corresponding author. and titration method using a $\mathrm{pH}-$ and/or ion selective electrodes (ISE) [10-12]. Potentiometric titration using an ISE is a very conventional approach that is used to directly and easily measure the activity of free (uncomplexed) metal ions. Although a few ion-selective electrodes have been developed for the potentiometric determination of trivalent lanthanide and actinide ions [13-16], no application to determine the formation constant has been reported. Recently, we developed a novel technique to determine the formation constants of trivalent metal ions with carboxylic acid electrochemically, using a liquid membrane electrode [17,18]. The ISE exhibited a Nernstian response to a wide range of $\mathrm{pH}$ values, as well as various concentrations of $\mathrm{Eu}^{3+}$ as an analogue of $\mathrm{Am}^{3+}$ and $\mathrm{Cm}^{3+}$, along with a fairly good response time. In the present study, a titration technique using an ISE was utilized for the systematic measurement of the formation constants of europium with three humic substances. The constants were also determined using the traditional batch solvent extraction method for comparison.

\section{Experimental}

\subsection{Reagents}

The studied humic substance materials, humic acid (HA) and fulvic acid (FA), are commercial powders that are available from the International Humic Substances Society (IHSS) and Sigma-Aldrich Co. The Sigma-Aldrich 
humic acid in sodium form was purified prior to use following the known protocol (abbreviated as ALHA) [19], and has been characterized [20,21]. The IHSS HA (as SHA, Eliot soil humic acid, code 1S102H) and FA (as SFA, Suwanee river fulvic acid, code 1S101F), which have also been well characterized as standards for environmental organic matter [22], were used without further purification. Additional aqueous solutions were prepared using ultrapure Milli-Q water (Millipore) with a resistivity of $18.2 \mathrm{M} \Omega / \mathrm{cm}$. All of the chemicals were of analytical grade.

\subsection{Titration with ISE}

Prior to the titration to determine the formation constants of Eu(III) with the humic substances, the applicability of the present ISE was checked. A fresh nitrobenzene solution containing $\mathrm{Eu}(\mathrm{III})$-bis(diphenylphosphoryl)methane (BDPPM) complex was prepared using an ion-pair solvent extraction with $\mathrm{Na}$ tetraphenylborate $(\mathrm{TPhB})$ according to the procedure reported previously [17]. The concentrations of the extracted species, Eu(BDPPM $)_{3} \cdot 3 \mathrm{TPhB}$ and BDPPM, were $1 \times 10^{-3} \mathrm{~mol} / \mathrm{dm}^{3}(\mathrm{M})$ and $1 \times 10^{-2} \mathrm{M}$, respectively. As shown in Scheme 1, the inner solution of ISE was $1 \times 10^{-3} \mathrm{M} \mathrm{Eu}^{3+}$ at $\mathrm{pH} \mathrm{2,} \mathrm{and} \mathrm{the} \mathrm{identical}$ supporting electrolyte, $0.1 \mathrm{M} \mathrm{LiCl}$, was adopted in the inner solution for the silver-silver chloride electrode (SSE1) and reference electrode (SSE2). The $\mathrm{pH}$ combination electrode was calibrated to measure the hydrogen ion concentration $\left(\left[\mathrm{H}^{+}\right]=10^{-\mathrm{pHc}}\right)$, based on the reference method $[23,24]$. A combination glass electrode (Kyoto Electronics, 98-100-C171) was used to measure the $\mathrm{pH}$, and the reference electrode was filled with $3.6 \mathrm{M} \mathrm{NaCl}+$ $0.4 \mathrm{M} \mathrm{NaClO}_{4}$.

The Eu-ISE measurements were performed using an automatic potentiometric titrator (AT-510, Kyoto Electro-nics) equipped with a 50-mL polypropylene vessel in a water bath at $298 \pm 1 \mathrm{~K}$, a magnetic Teflon stirrer, and a nitrogen gas purge system $(10-\mathrm{mL} / \mathrm{min})$. The potential, denoted as ISE potential $\left(\Delta V_{\mathrm{ISE}}\right)$, generated between SSE1 and SSE2, after a constant potential was attained, was measured using a potentiostat (Hokuto-denko, HA151 ), and recorded by an $\mathrm{X}-\mathrm{Y}$ recorder (Riken-denshi, $\mathrm{SP}-\mathrm{K} 2 \mathrm{~V})$.

0.1-mL portions of the titrants of the humic substances (ALHA, SHA, SFA) were added to $10 \mathrm{ml}$ of the $10^{-5}$ and $3 \times 10^{-5} \mathrm{M} \mathrm{Eu}^{3+}$ solutions $(I=0.1$ and $0.01 \mathrm{M}(\mathrm{NaCl}))$ at intervals of $300 \mathrm{sec}$. The $\mathrm{pH}_{\mathrm{c}}$ was automatically kept constant by adding $\mathrm{NaOH}$ solution. The ionic strength of the test solution was controlled to be 0.1 and 0.01 using the $\mathrm{Na}^{+}-\mathrm{Cl}^{-}$system throughout the experiment.

\subsection{Solvent Extraction}

The procedure for determining the formation constants by solvent extraction was described previously in detail

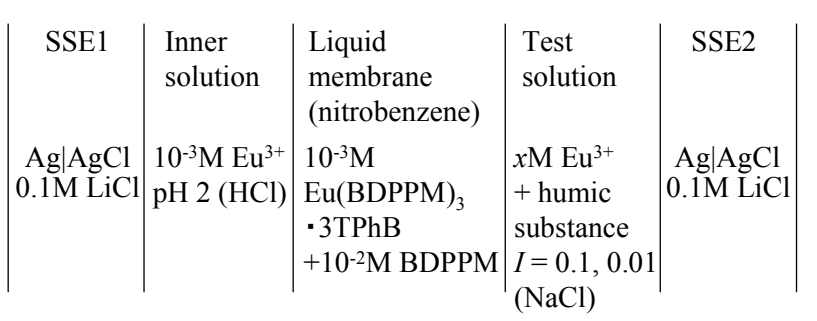

Scheme 1. ISE cell configuration.

[25]. In brief, in order to obtain data about distribution ratio $D$, an aqueous phase, containing various concentrations $\left(10^{-6}-10^{-3} \mathrm{M}\right)$ of the humic substances and $\mathrm{Eu}$ $\left(10^{-6}-3 \times 10^{-5} \mathrm{M}\right)$, was adjusted to the desired $\mathrm{pH}_{\mathrm{c}}$ using sodium hydroxide, perchloric acid. The organic phase of xylene contained TTA (2-thenoyltrifluoroacetone) as an extractant and TBP (tri- $n$-butyl phosphate) as a synergist. The aqueous and organic phases were shaken for $6 \mathrm{~h}$ at $298 \pm 1 \mathrm{~K}$. After the phase separation, the $\mathrm{pH}_{\mathrm{c}}$ of the aqueous phase was measured and taken as the equilibrium $\mathrm{pH}$. The $\mathrm{Eu}(\mathrm{III})$ concentrations in both phases were measured using inductively coupled plasma mass spectrometry, where the concentration in the organic phase was determined after stripping with $0.1 \mathrm{M} \mathrm{HNO}_{3}$. Because the recovery of Eu(III) was usually more than $95 \%$, no serious unexpected reactions such as precipitation or a third phase formation were observed.

\section{Theoretical}

\subsection{Determination of Apparent Formation Constants by Titration with ISE}

Because of the heterogeneous chemical property of humic substances, the number of functional groups per molecule and the molecular weight cannot be clearly defined. Therefore, by analogy with Langmuir's adsorption isotherm, the apparent formation constant, $\beta_{\text {app }}$, is defined as follows [10],

$$
\beta_{\text {app }}=\frac{[\mathrm{EuL}]}{\left[\mathrm{Eu}^{3+}\right]\left[\mathrm{R}^{-}\right]}
$$

where $\left[\mathrm{Eu}^{3+}\right]$ and $[\mathrm{EuL}]$ are the concentrations of free metal ions and metal ions bound with humic substance L, and $\left[\mathrm{R}^{-}\right]$is the concentration of the dissociated functional group in eq $/ \mathrm{dm}^{3}$. Here, in the absence of metal ions, $\left[\mathrm{R}^{-}\right]$ is given on the basis of the charge balance, $\left[\mathrm{H}^{+}\right]+\left[\mathrm{Na}^{+}\right]$ $=\left[\mathrm{R}^{-}\right]+\left[\mathrm{OH}^{-}\right]+\left[\mathrm{CLO}_{4}^{-}\right]$, and

$$
\begin{aligned}
& {\left[\mathrm{R}^{-}\right]=10^{-\mathrm{pHc}}-10^{(\mathrm{pHc}-\mathrm{p} K \mathrm{~W})}} \\
& +\frac{c_{\mathrm{Na}} V_{\mathrm{ini}}+c_{\mathrm{Na}}^{\prime} V_{\mathrm{add}}-c_{\mathrm{ClO}_{4}} V_{\mathrm{ini}}-c_{\mathrm{ClO}_{4}}^{\prime} V_{\mathrm{add}}}{V_{\mathrm{ini}}+V_{\mathrm{add}}}
\end{aligned}
$$

where $c_{\mathrm{Na}}$ and $c_{\mathrm{ClO}_{4}}$ are the concentrations of sodium and perchlorate ions in the initial test solution, $c_{\mathrm{Na}}^{\prime}$ and $c_{\mathrm{ClO}}^{\prime}{ }_{4}$ are the concentrations of the titrant solutions, $V_{\text {ini }}$ 
is the initial volume, $V_{\text {add }}$ is the added titrant volume, and $\mathrm{pH}_{\mathrm{c}}$ is the negative logarithm of the absolute hydrogen ion concentration $\left(-\log \left[\mathrm{H}^{+}\right]\right)$. The ion product $\left(\mathrm{p} K_{\mathrm{w}}\right)$ was used from the literature [26]. By using the apparent protonation constant, $K_{\text {app }}$, as

$$
K_{\text {app }}=\frac{[\mathrm{HR}]}{\left[\mathrm{H}^{+}\right]\left[\mathrm{R}^{-}\right]}
$$

the degree of dissociation, $\alpha$, can be written as

$$
\begin{aligned}
\alpha & =\left[\mathrm{R}^{-}\right] /\left([\mathrm{HR}]+\left[\mathrm{R}^{-}\right]\right) \\
& =\frac{1}{1+\left([\mathrm{HR}] /\left[\mathrm{R}^{-}\right]\right)}=\frac{1}{1+K_{\mathrm{app}}\left[\mathrm{H}^{+}\right]}
\end{aligned}
$$

Similar to previous works [20,27], two major protondissociable functional groups - carboxylic and phenolic groups - are considered. Then, the two apparent protonation constants, $K_{\mathrm{app}, i}(i=1,2)$, can be rewritten as a function of $\mathrm{pH}$ and $\left[\mathrm{Na}^{+}\right]$,

$$
\log K_{\mathrm{app}, i}=\log K_{i}+m_{i} \mathrm{pH}_{\mathrm{c}}-b \log \left[\mathrm{Na}^{+}\right]
$$

where $m_{i}, b$, and $\log K_{i}$ are the characteristic constant parameters of the humic substance [28].

At a given $I$, the $\left[\mathrm{R}^{-}\right]$is defined by the sum of two dissociated functional groups of the humic substance $\left(R^{-}\right)$in $\mathrm{meq} / \mathrm{g}$, where $j \mathrm{~g}$ of the humic substance is dissolved in $V$ $\mathrm{dm}^{3}$ of the solution,

$$
\left[\mathrm{R}^{-}\right]=\left(\mathrm{R}^{-}\right) \frac{j}{10^{3} V}
$$

The $\left(\mathrm{R}^{-}\right)$is given by

$$
\begin{aligned}
\left(\mathrm{R}^{-}\right) & =C_{1}^{w} \alpha_{1}+C_{2}^{w} \alpha_{2}=\sum_{i} \frac{C_{i}^{w}}{1+K_{\mathrm{app}, i}\left[\mathrm{H}^{+}\right]} \\
& =\sum_{i} \frac{C_{i}^{w}}{1+10^{\wedge}\left\{\left(\frac{\log K_{i}}{1-m_{i}}-\mathrm{pH}_{\mathrm{c}}\right)\left(1-m_{i}\right)-b \log \left[\mathrm{Na}^{+}\right]\right\}}
\end{aligned}
$$

$(i=1,2)$

where $C_{1}^{w}$ and $C_{2}^{w}$ mean the total carboxylic and phenolic group concentrations, respectively, and $C_{1}^{w}+$ $C_{2}^{w}=C_{\text {tot }}^{w}$ in meq $/ \mathrm{g}$. These parameters, $C_{i}^{w}, \log K_{i} /\left(1-m_{i}\right)$, and $m_{i}$, were determined using a fitting analysis with Equations (2) and (6) [21,29], and are summarized in Table 1. The values are used for the calculation of the apparent formation constants, as described below.

The total concentration of the proton-exchanging sites, $C_{\mathrm{R}}$, and metal ion $[\mathrm{Eu}]_{\text {tot }}$ in $\mathrm{mol} / \mathrm{dm}^{3}$ are described as

$$
\begin{gathered}
C_{\mathrm{R}}=C_{\mathrm{R} 1}+C_{\mathrm{R} 2}=C_{\mathrm{tot}}^{w}\{\mathrm{HS}\} / 10^{3} \\
=[\mathrm{HR}]+\left[\mathrm{R}^{-}\right]+m[\mathrm{EuL}] \\
{[\mathrm{Eu}]_{\mathrm{tot}}=\left[\mathrm{Eu}^{3+}\right]+[\mathrm{EuL}]}
\end{gathered}
$$

Table 1. Characteristics of humic substances.

\begin{tabular}{cccc}
\hline HS & SFA [29] & SHA [21] & ALHA [21] \\
\hline Origin & IHSS & IHSS & Aldrich \\
$C_{1}^{w}$ & $1 \mathrm{~S} 101 \mathrm{~F}$ & $1 \mathrm{~S} 102 \mathrm{H}$ & $01816 \mathrm{HH}$ \\
$\log K_{1} /$ & 4.78 & 3.99 & 4.27 \\
$\left(1-m_{1}\right)$ & 3.27 & 3.69 & 4.29 \\
$m_{1}$ & 0.70 & 0.66 & 0.67 \\
$C_{2}^{w}$ & 1.44 & 1.42 & 1.01 \\
$\log K_{2} /$ & 8.98 & 9.82 & 9.46 \\
$\left(1-m_{2}\right)$ & 0.83 & 0.73 & 0.80 \\
$m_{2}$ & 0.11 & 0.28 & 0.09 \\
$b$ & 0.30 & 0.36 & 0.24 \\
$C_{2}^{w} / C_{1}^{w}$ & & & \\
\hline
\end{tabular}

where $\{\mathrm{HS}\}$ is the mass concentration of the humic substance in $\mathrm{g} / \mathrm{dm}^{3}$, and $m$ is the number of functional groups binding a europium ion and is assumed to be 3 , which is equal to the charge number of $\mathrm{Eu}^{3+}$ in the present study. When complex EuL is formed with each binding site, the three proton-exchanging groups are assigned to be formally satisfied with a charge-neutralized complex. Then, Equation (8) can be replaced by

$$
\begin{aligned}
{\left[\mathrm{R}^{-}\right] } & =\left(C_{\mathrm{R}}-3[\mathrm{EuL}]\right) \alpha \\
& =\left(C_{\mathrm{R}}-3\left([\mathrm{Eu}]_{\text {tot }}-\left[\mathrm{Eu}^{3+}\right]\right)\right)\left(\mathrm{R}^{-}\right) / C_{\text {tot }}^{w}
\end{aligned}
$$

In the titration experiment with ISE, the concentration of free metal ion $\left[\mathrm{Eu}^{3+}\right]$ can be measured directly. The observed ISE potential, $\Delta V_{\mathrm{ISE}}$, in $\mathrm{mV}$, which arises from the different activities, $a_{\mathrm{Eu}, \mathrm{SSE}}$, of the free $\mathrm{Eu}^{3+}$ ions between SSE1 and SSE2 in Scheme 1, is described by the following Nernstian response,

$$
\Delta V_{\mathrm{ISE}}=\frac{R T}{3 F}\left(\ln a_{\mathrm{Eu}, \mathrm{SSE} 1}-\ln a_{\mathrm{Eu}, \mathrm{SSE} 2}\right)+\mathrm{const}
$$

where $R$ is a gas constant equal to $8.314 \mathrm{~J} / \mathrm{K} / \mathrm{mol}, T$ is the temperature $(\mathrm{K})$, and $F$ is the Faraday constant, which is equal to $96500 \mathrm{C} / \mathrm{mol}$. When $a_{\mathrm{Eu}} \approx\left[\mathrm{Eu}^{3+}\right]$ can be assumed in the present experimental condition of low $\left[\mathrm{Eu}^{3+}\right]$, the linear relationship between the potential and concentration, with a slope of ca. $20 \mathrm{mV} /$ decade, is shown as,

$$
\Delta V_{\mathrm{ISE}}=19.7 \log \left[\mathrm{Eu}^{3+}\right]+\mathrm{const}
$$

In the previous work, this linearity was observed in the presence of carboxylic acids such as malonic acid [18]. While interference from a coexisting trivalent ion might occur [17], this indicates that BDPPM is a highly sensitive ionophore for a single trivalent ion of the lanthanide or actinide series. Thus, according to Equations (9), (10), and (12), the apparent formation constant, $\beta_{\text {app }}$, in Equa- 
tion (1) is determined.

\subsection{Determination of $\boldsymbol{\beta}_{\text {app }}$ by Solvent Extraction}

The extraction equilibrium constant, $K_{\mathrm{ex}}$, of europium for

$$
\begin{aligned}
& \mathrm{Eu}^{3+}+3 \mathrm{HTTA}_{\text {org }}+l \mathrm{TBP}_{\text {org }} \rightleftharpoons \\
& \mathrm{Eu}\left(\mathrm{TTA}^{-}\right)_{3}(\mathrm{TBP})_{l, \text { org }}+3 \mathrm{H}^{+}
\end{aligned}
$$

is described as

$$
K_{\mathrm{ex}}=\frac{\left[\mathrm{Eu}\left(\mathrm{TTA}^{-}\right)_{3}(\mathrm{TBP})_{l}\right]_{\mathrm{org}}\left[\mathrm{H}^{+}\right]^{3}}{\left[\mathrm{Eu}^{3+}\right][\mathrm{HTTA}]_{\mathrm{org}}^{3}[\mathrm{TBP}]_{\mathrm{org}}^{l}}
$$

where the subscript org denotes the species in the organic phase. When the complex formation of $\mathrm{Eu}^{3+}$ by $\mathrm{TTA}^{-}$ and the hydrolysis reaction by $\mathrm{OH}^{-}$are negligible in the aqueous phase at $\mathrm{pH}_{\mathrm{c}}<5$, the distribution ratio of $\mathrm{Eu}(\mathrm{III})$, $D_{0}$, in the absence of a complexing ligand can be simply expressed by

$$
D_{0}=[\mathrm{Eu}]_{\mathrm{org}} /\left[\mathrm{Eu}^{3+}\right]
$$

Then, distribution ratio $D$ in the presence of a humic substance is given by

$$
\begin{aligned}
D & =[\mathrm{Eu}]_{\mathrm{org}} /[\mathrm{Eu}]_{\mathrm{tot}}=[\mathrm{Eu}]_{\mathrm{org}} /\left[\left[\mathrm{Eu}^{3+}\right]+[\mathrm{EuL}]\right] \\
& =\frac{[\mathrm{Eu}]_{\mathrm{org}}}{\left[\mathrm{Eu}^{3+}\right]\left(1+\beta_{\text {app }}\left[\mathrm{R}^{-}\right]\right)}
\end{aligned}
$$

where the "initial" concentration of $\mathrm{Eu}$ is defined as

$$
[\mathrm{Eu}]_{\mathrm{ini}}=\left[\mathrm{Eu}^{3+}\right]+[\mathrm{EuL}]+[\mathrm{Eu}]_{\mathrm{org}}
$$

Finally, from the difference between the presence $(D)$ and absence $\left(D_{0}\right)$ of humic substances,

$$
\beta_{\text {app }}=\left(D_{0} / D-1\right) /\left[\mathrm{R}^{-}\right]
$$

The $\beta_{\text {app }}$ values in Equation (18) can be determined, where the $\left[\mathrm{R}^{-}\right]$is described by Equations (4) and (10), as follows,

$$
\left[\mathrm{R}^{-}\right]=\alpha \cdot\left(C_{\mathrm{R}}-3[\mathrm{Eu}]_{\mathrm{tot}}\left(1-D / D_{0}\right)\right)
$$

\section{Results and Discussion}

\subsection{Electrochemical Response of ISE}

The electrochemical properties of the present ISE were characterized prior to use. Figure 1 shows the variation in $\Delta V_{\text {ISE }}$ as a function of the logarithm of $\left[\mathrm{Eu}^{3+}\right]$ at different ionic strengths in the absence of humic substances. Although deviations from the Nernstian behavior (apparently as a result of the $\mathrm{NaCl}$ background) were observed in solutions containing lower europium concentrations, the ISE gave a good linear response with a slope of ca. $20 \mathrm{mV} /$ decade for $\mathrm{Eu}^{3+}$ in the $\log \left[\mathrm{Eu}^{3+}\right]$ range of -6 -3 at $I=0.01$ and $-5.3--3$ at $I=0.1$. The interference with the potential response by competitive ions is not

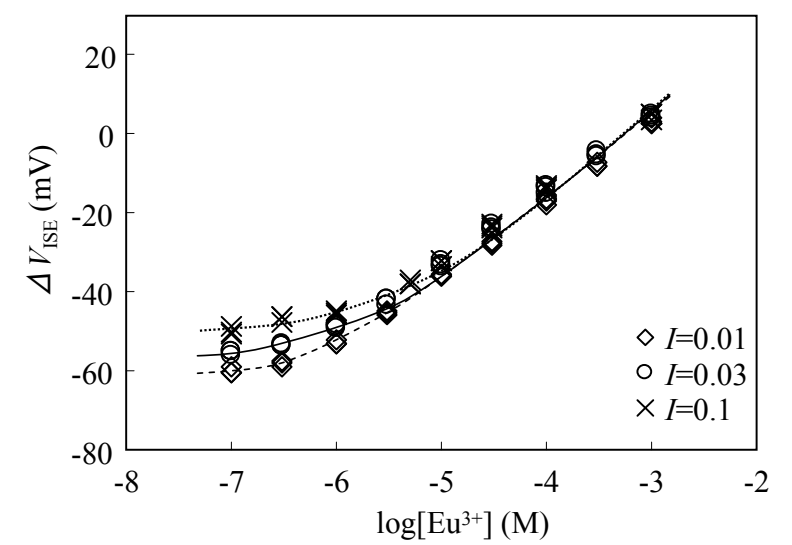

Figure 1. Potential response of ISE for $\mathrm{Eu}^{3+}$ at different ionic strengths of $\mathrm{NaCl}\left(\mathrm{pH}_{\mathrm{c}} 5,298 \mathrm{~K}\right)$.

considered here, because the quantification of the selectivity of the present ISE among the actinide series, $\mathrm{Pu}^{3+}$ vs. $\mathrm{UO}_{2}^{2+}, \mathrm{U}^{4+}, \mathrm{NpO}_{2}^{+}$, and $\mathrm{Pu}^{4+}$, has been investigated, and showed good selectivity for the different valence state ions [17]. Indeed, no other metal ions, except $\mathrm{Na}$ and anions, would be present in this experiment.

The electrode response on the $\mathrm{pH}_{\mathrm{c}}$ of the test solutions was investigated as shown in Figure 2. The reading potential value remained constant at the $\mathrm{pH}_{\mathrm{c}}$ range of $3-6$, while the values at $\mathrm{pH}_{\mathrm{c}} 5$ decreased slightly because of the competitive response for protons. In addition, a flat ISE response was found in a wide range of $\left[\mathrm{Eu}^{3+}\right]$.

At europium concentrations of $10^{-3}-5 \times 10^{-6} \mathrm{M}$, the potential remained sufficiently stable over $6 \mathrm{~h}$, and good reproducible readings in several sets of titration experiments in the system of the carboxylic acid-Eu complexation were obtained [18]. Similarly, the reading potential values remained constant after repetitive use of ISE in the present humic substance system, suggesting an undesirable reaction such as the sorption and the dissolution of humic substance for the ISE did not occur. Here, in order to investigate the dynamic response time of the ISE, the potential change in the test solution before and after the addition of $\mathrm{Eu}^{3+}$ was recorded with time. As shown in Figure 3, the addition of $10^{-2} \mathrm{M} \mathrm{EuCl}_{3}$ to the initial europium solution induced a sudden increase in the reading potential. The occurrence of this phenomenon just after the addition $\left(t_{\mathrm{c}} \sim 0\right)$ must have been caused by a local increase in the Eu concentration near the electrode. In fact, the potential became stable within $30 \mathrm{sec}$, suggesting a homogeneous condition.

A similar behavior was observed in the presence of a humic substance. The $\left[\mathrm{Eu}^{3+}\right]$ evaluated according to Equation (12) over time is shown in Figure 4. When the ALHA portion was dropped into the test solution to attain $C_{\mathrm{R}}=0$ to $10^{-4} \mathrm{eq} / \mathrm{dm}^{3}$, the free $\mathrm{Eu}^{3+}$ ions were rapidly consumed as a result of the complexation with the humic acid, and a constant steady state was achieved 


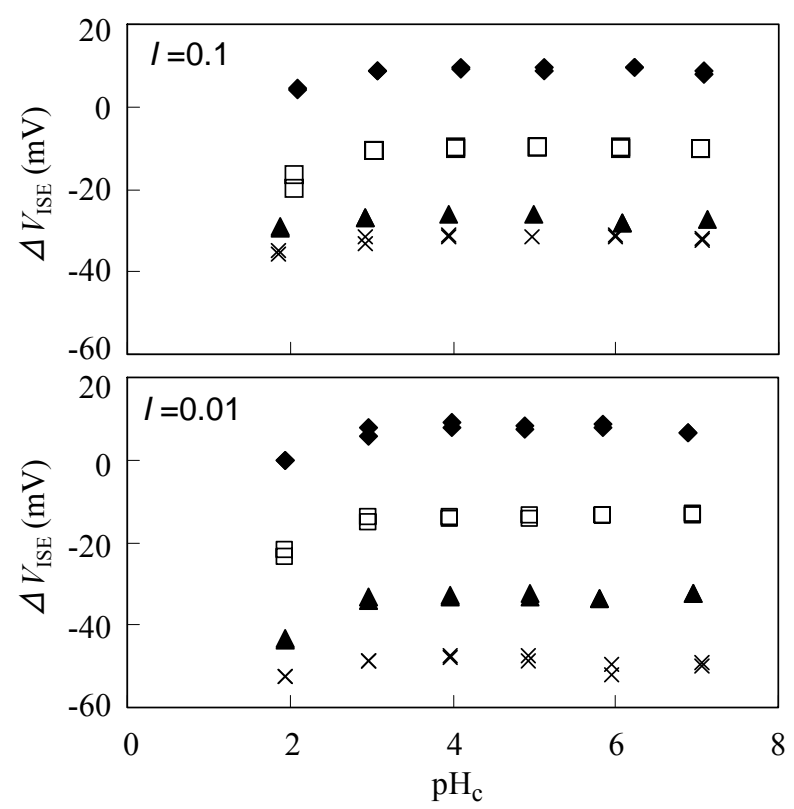

Figure 2. pH dependence of ISE response for different concentrations of $\mathrm{Eu}^{3+}$ at $I=0.1$ (top) and 0.01 (bottom); $\log \left[\mathrm{Eu}^{3+}\right]=-3(\diamond),-4(\square),-5(\Delta)$, and -5.3 for $I=0.1$ and -6 for $0.01(\times)$.

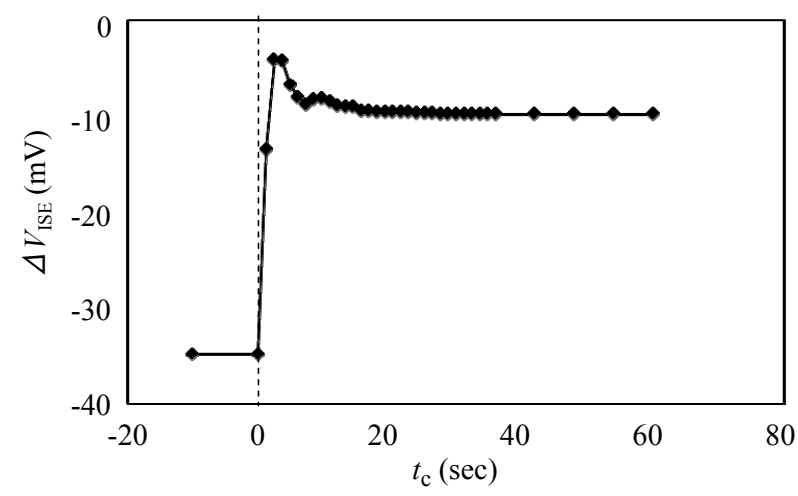

Figure 3. Potential response change from $\log \left[\mathrm{Eu}^{3+}\right]=-5.3$ to -4 at $\mathrm{pH}_{\mathrm{c}}=5$ and $I=0.1$.

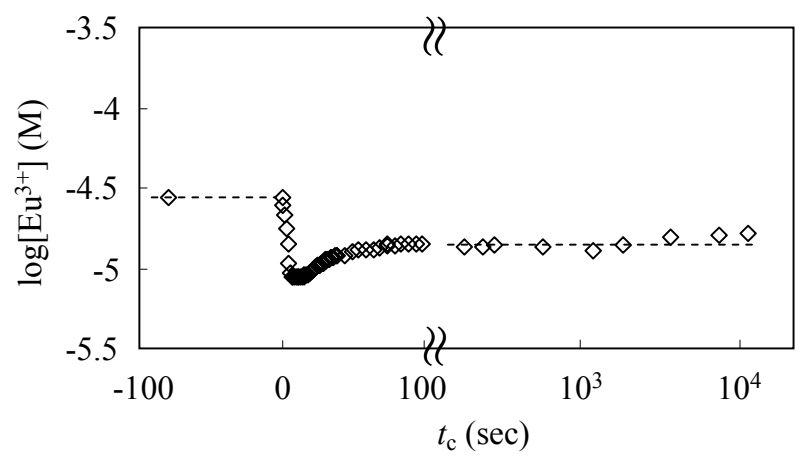

Figure 4. Time dependence of free Eu ion concentration with addition of ALHA solution; $20 \mathrm{ml}$ of $[\mathrm{Eu}]_{\text {tot }}=3 \times 10^{-5}$ $M$ solution $\left(\mathrm{pH}_{\mathrm{c}}=5, I=0.1\right)$, and the titrant of $1 \mathrm{ml}$ ALHA is $C_{\mathrm{R}}=2 \times 10^{-3} \mathrm{eq} / \mathrm{dm}^{3}$. after $100 \mathrm{sec}$. In the following experiment, the expected $C_{\mathrm{R}}$ change for each drop was $<10^{-5} \mathrm{eq} / \mathrm{dm}^{3}$ and the dropping interval was $300 \mathrm{sec}$. Thus, it is possible to conclude that this good property of ISE meets the basic requirements of the present study.

\subsection{Titration Plot}

Potentiometric titrations were made under the controlled constant $\mathrm{pH}_{\mathrm{c}}$. The typical result of the logarithm of the europium concentration as a function of $C_{\mathrm{R}}$ is shown in Figure 5. Because of the complexation of $\mathrm{Eu}$ with humic substances, the free europium ion concentration decreased with an increase in the amount of humic substances. The apparent formation constants, $\beta_{\text {app }}$, at each titration point were calculated based on the determined free $\left[\mathrm{Eu}^{3+}\right]$.

\subsection{Apparent Formation Constants}

The dependency of $C_{\mathrm{R}}$ on the apparent formation constants, $\beta_{\text {app }}$, is shown in Figure 6. Because of the heterogeneous property of $\mathrm{HA}$, the $\beta_{\text {app }}$ value varied with the $\mathrm{pH}$, metal ion and humic substance concentrations, and ionic strength. In the presence of excess $C_{\mathrm{R}}$ to the $\left[\mathrm{Eu}^{3+}\right]$, the $\mathrm{Eu}^{3+}$ ions preferentially interacted with the stronger coordination sites [30]. Then, the $\beta_{\text {app }}$ values would increase. On the other hand, the weaker coordination sites need to be used for complexation under the condition of a smaller amount of $C_{\mathrm{R}}$. A similar explanation is available from the viewpoints of the $\mathrm{Eu}$ concentration and ionic strength. At a given $\log C_{\mathrm{R}}$ condition, the series of $\beta_{\text {app }}$ at $[\mathrm{Eu}]_{\mathrm{tot}}=3 \times 10^{-5} \mathrm{M}$ are lower than that at $10^{-5} \mathrm{M}$, and the higher amount of $\mathrm{Na}^{+}(I=0.1)$ effectively interferes with the occupation of $\mathrm{Eu}^{3+}$ on the binding sites of HA. Such an ionic strength effect on the metal complexation has been discussed by several researchers. Some model concepts have been represented by a linear relationship between the apparent formation constants and ionic strength with an empirical parameter [10,31].

The $\beta_{\text {app }}$ data for SHA determined using the solvent extraction method, are also plotted in Figure 6. Although the $C_{\mathrm{R}}$ range examined was different from each method, the increasing tendency of $\beta_{\text {app }}$ with an increase of $C_{\mathrm{R}}$ can be observed, suggesting the heterogeneous property of SHA. Thus, the data will be useful for constructing a semi-empirical model of the formation constants of metal ion-humic substance complexation [30]. On the other hand, Figure 7 shows the lower impact of $I$ and $[\mathrm{Eu}]$ on the $\beta_{\text {app }}$ for the SFA system. Even at the higher $\log C_{\mathrm{R}}$ above -3.5 , the $\beta_{\text {app }}$ value did not increase with increasing $C_{\mathrm{R}}$.

A comparison of the $\beta_{\text {app }}$ data for the three humic substances under similar solution conditions is shown in Figure 8. The relatively high $\beta_{\text {app }}$ values for SHA and 


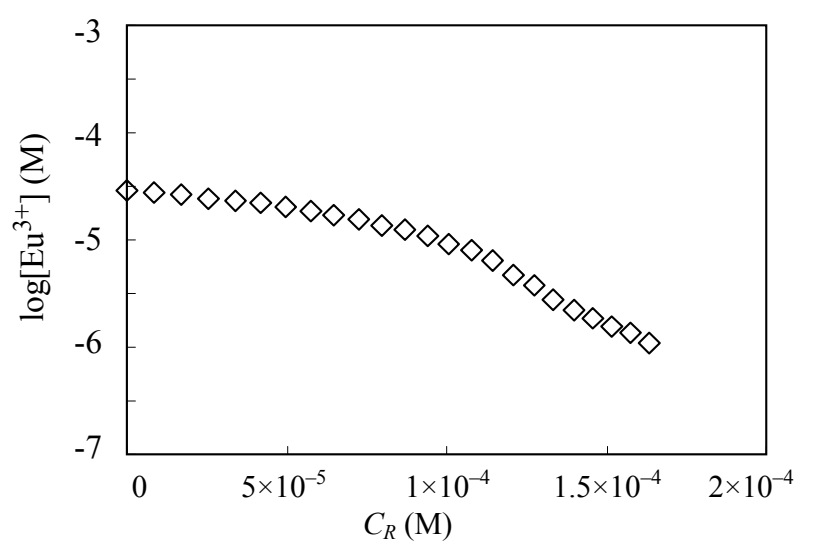

Figure 5. Titration plots of logarithm of free europium concentration as function of $C_{\mathrm{R}}$ at constant $\mathrm{pH}_{\mathrm{c}}$ of 4.87 and $I=$ $0.01(\mathrm{NaCl})$. The $[\mathrm{Eu}]_{\text {tot }}$ is $3 \times 10^{-5} \mathrm{M}$, the titrant is $2 \times 10^{-3}$ M of ALHA.
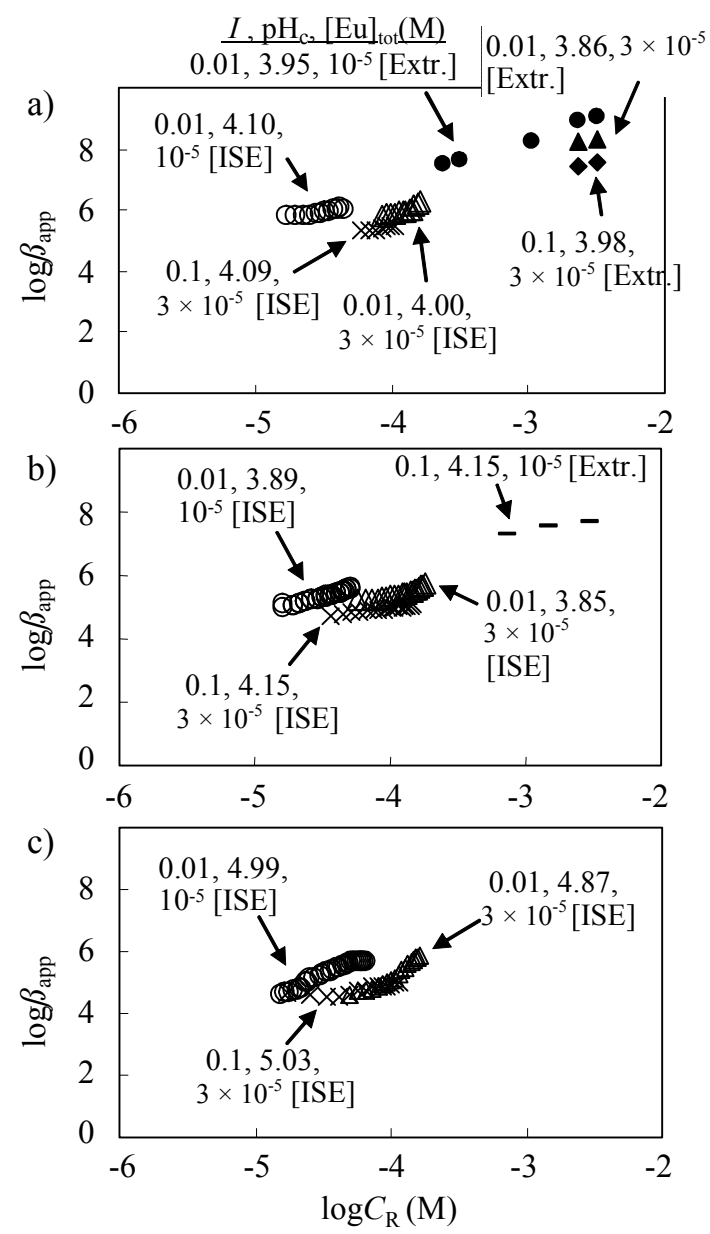

Figure 6. Dependence of $\log C_{\mathrm{R}}, I,[\mathrm{Eu}]_{\text {tot }}$, and analytical method on $\log \beta_{\text {app }}$ : (a) SHA; (b, c) ALHA.

ALHA compared to SFA might be related to the $\log K /(1-m)$ value in Table 1 , which provided a measure of the strength of proton binding as the acidity. The high value is affected by strong intramolecular hydrogen

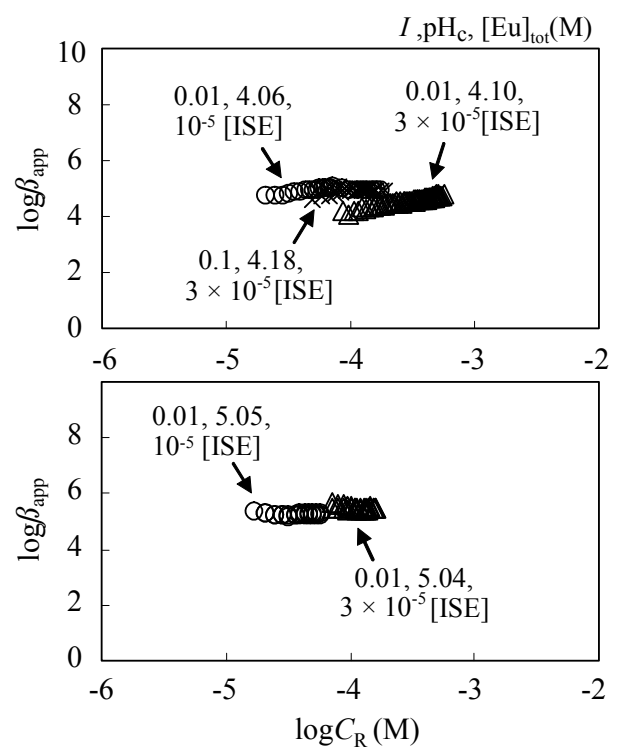

Figure 7. Dependence of $\log C_{\mathrm{R}}$, $[\mathrm{Eu}]_{\text {tot }}$ and $I$ on $\log \beta_{\text {app }}$ for SFA.
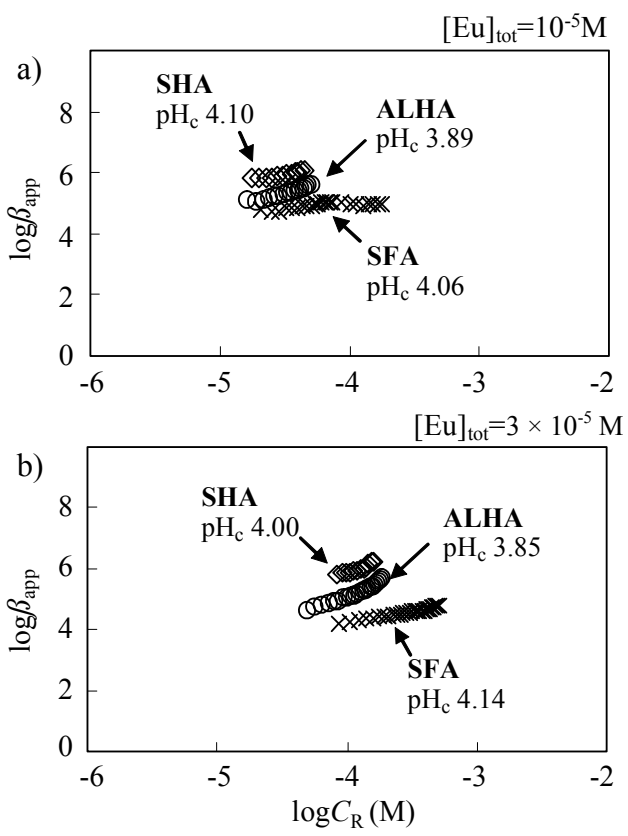

Figure 8. Intercomparison of $\log \boldsymbol{\beta}_{\text {app }}$ for humic substances at $\mathrm{pH}_{\mathrm{c}} \sim 4, I=0.01(\mathrm{NaCl})$, and $[\mathrm{Eu}]_{\text {tot }}=10^{-5} \mathrm{M}$ (a) and $3 \times$ $10^{-5} \mathrm{M}(\mathrm{b})$. Data were obtained by the titration with ISE.

bonds among the neighboring multi-functional groups. This fact might introduce a strong chelate complexation, resulting in the higher $\beta_{\text {app }}$ values. However, it is difficult to correlate the ratio of the number of carboxylic and phenolic functional groups, $C_{2}^{w} / C_{1}^{w}$, to the reason for the different $\beta_{\text {app }}$ values. The other reason would be the different molecular weights and sizes of the humic substances from the electrostatic point of view. In general, the larger molecules of HA has a greater tendency to 
aggregate than FA. If the polyvalent metal ion $\mathrm{Eu}^{3+}$ was incorporated by the aggregation, the $\beta_{\text {app }}$ might increase.

\section{Conclusion}

The apparent formation constants of europium ions with humic acid and fulvic acid could be determined by potentiometric titration using an ion selective electrode (ISE) under several solution conditions. The electrode exhibited a stable and quick Nernstian response during the period of measurement. Unlike the batch-type solvent extraction method, the present titration can acquire multiple data points at once without troublesome experimental preparations.

\section{REFERENCES}

[1] J. I. Kim and T. Sekine, "Complexation of Neptunium(V) with Humic-Acid," Radiochimica Acta, Vol. 55, No. 4, 1991, pp. 187-192.

[2] V. Moulin, J. Tits and G. Ouzounian, "Actinide Speciation in the Presence of Humic Substances in Natural-Water Conditions," Radiochimica Acta, Vol. 58, 1992, pp. 179-190.

[3] Y. Takahashi, Y. Minai, S. Ambe, Y. Makide, F. Ambe and T. Tominaga, "Simultaneous Determination of Stability Constants of Humate Complexes with Various Metal Ions Using Multitracer Technique," Science of the Total Environment, Vol. 198, No. 1, 1997, pp. 61-71. doi:10.1016/S0048-9697(97)05442-9

[4] D. Wenming, Z. Hongxia, H. Meide and T. Zuyi, "Use of the Ion Exchange Method for the Determination of Stability Constants of Trivalent Metal Complexes with $\mathrm{Hu}-$ mic and Fulvic Acids-Part I: $\mathrm{Eu}^{3+}$ and $\mathrm{Am}^{3+}$ Complexes in Weakly Acidic Conditions," Applied Radiation and Isotopes, Vol. 56, No. 6, 2002, pp. 959-965. doi:10.1016/S0969-8043(01)00055-0

[5] M. Schnitzer and S. I. M. Skinner, "Organo-Metallic Interactions in Soils: 7. Stability Constants of $\mathrm{Pb}^{++}-\mathrm{Ni}^{++}$, $\mathrm{Mn}^{++}-\mathrm{Co}^{++}-, \mathrm{Ca}^{++}$-, and $\mathrm{Mg}^{++}$-Fulvic Acid Complexes," Soil Science, Vol. 103, No. 4, 1967, pp. 247-252. doi:10.1097/00010694-196704000-00004

[6] M. Schnitzer and S. I. M. Skinner, "Organo-Metallic Interactions in Soils: 5. Stability Constants of $\mathrm{Cu}^{++}-, \mathrm{Fe}^{++}-$, and $\mathrm{Zn}^{++}$-Fulvic Acid Complexes," Soil Science, Vol. 102, No. 6, 1966, pp. 361-365. doi:10.1097/00010694-196612000-00002

[7] M. Caceci, "The Interaction of Humic-Acid with Europium(III) Complexation Strength as a Function of Load and pH," Radiochimica Acta, Vol. 39, 1985, pp. 51-56.

[8] J. H. Ephraim, "Heterogeneity as a Concept in the Interpretation of Metal-Ion Binding by Humic Substances-The Binding of Zinc by an Aquatic Fulvic Acid," Analytica Chimica Acta, Vol. 267, No. 1, 1992, pp. 39-45. doi:10.1016/0003-2670(92)85004-P

[9] M. A. Glaus, W. Hummel and L. R. Van Loon, "Equilibrium Dialysis-Ligand Exchange: Adaptation of the Method for Determination of Conditional Stability Constants of Radionuclide-Fulvic Acid Complexes," Analytica Chimica Acta, Vol. 303, No. 2-3, 1995, pp. 321-331. doi:10.1016/0003-2670(94)00534-S

[10] A. Kirishima, T. Ohnishi, N. Sato and O. Tochiyama, "Simplified Modeling of the Complexation of Humic Substance for Equilibrium Calculations," Journal of $\mathrm{Nu}$ clear Science and Technology, Vol. 47, No. 11, 2010, pp. 1044-1054. doi:10.1080/18811248.2010.9711669

[11] J. G. Hering and F. M. M. Morel, "Humic Acid Complexation Calcium and Copper," Environmental Science and Technology, Vol. 22, No. 10, 1988, pp. 1234-1237. doi:10.1021/es00175a018

[12] J. P. Pinheiro, A. M. Mota and M. F. Benedetti, "Lead and Calcium Binding to Fulvic Acids: Salt Effect and Competition," Environmental Science and Technology, Vol. 33, No. 19, 1999, pp. 3398-3404. doi:10.1021/es990210f

[13] T. Ito, C. Goto and K. Noguchi, "Lanthanoid Ion-Selective Solvent Polymeric Membrane Electrode Based on 1-Phenyl-3-methyl-4-octadecanoyl-5-pyrazolone," Analytica Chimica Acta, Vol. 443, No. 1, 2001, pp. 41-51. doi:10.1016/S0003-2670(01)01192-8

[14] M. R. Ganjali, N. Davarkhah, H. Ganjali, B. Larijani, P. Norouzi and M. Hossieni, "A Novel Europium(III) Sensor Based on 4E-4-(2-phenylviazenyl)-2-((E)-(2-aminoethylimino)methyl)phenol," International Journal of Electrochemical Science, Vol. 4, No. 6, 2009, pp. 762-771.

[15] J. B. Harrell, A. D. Jones and G. R. Choppin, "A Liquid Ion-Exchange Membrane Electrode for Polyvalent Cations," Analytical Chemistry, Vol. 41, No. 11, 1969, pp. 1459-1462. doi: $10.1021 / \mathrm{ac} 60280 \mathrm{a} 026$

[16] D. A. Chowdhury, T. Ogata, S. Kamata and K. Ohashi, "Samarium(III)-Selective Electrode Using Neutral Bis (thiaalkylxanthato)alkanes," Analytical Chemistry, Vol. 68, No. 2, 1996, pp. 366-370. doi:10.1021/ac950814b

[17] Y. Kitatsuji, H. Aoyagi, Z. Yoshida and S. Kihara, "Plutonium(III)-Ion Selective Electrode of Liquid Membrane Type Using Multidentate Phosphine Oxide Ionophore," Analytica Chimica Acta, Vol. 387, No. 2, 1999, pp. 181187. doi:10.1016/S0003-2670(99)00121-X

[18] T. Sasaki, H. Yoshida, Y. Kitatsuji, I. Takagi and H. Moriyama, "Formation Constants of Eu(III)-Carboxylates Determined by Ion Selective Liquid Membrane Electrode," Chemistry Letters, Vol. 40, 2011, pp. 870-871. doi:10.1246/c1.2011.870

[19] J. I. Kim, G. Buckau, G. H. Li, H. Duschner and N. Psarros, "Characterization of Humic and Fulvic Acids from Gorleben Groundwater," Fresenius Journal of Analytical Chemistry, Vol. 338, No. 3, 1990, pp. 245-252. doi:10.1007/BF00323017

[20] A. Kirishima, T. Ohnishi, N. Sato and O. Tochiyama, "Determination of the Phenolic-Group Capacities of Humic Substances by Non-Aqueous Titration Technique," Talanta, Vol. 79, No. 2, 2009, pp. 446-453. doi:10.1016/j.talanta.2009.04.008

[21] T. Sasaki, S. Aoyama, H. Yoshida, Y. Kulyako, M. Samsonov, T. Kobayashi, I. Takagi, B. Miyasoedov and H. Moriyama, "Apparent Formation Constants of $\mathrm{Pu}(\mathrm{IV})$ and Th(IV) with Humic Acids Determined by Solvent Extrac- 
tion Method," Radiochimica Acta, 2012, in press.

[22] "International Humic Substances Society," 2012. http://www.humicsubstances.org

[23] G. Gran, "Determination of the Equivalence Point in Potentiometric Titrations. Part II," Analyst, Vol. 77, No. 920, 1952, pp. 661-671. doi:10.1039/an9527700661

[24] K. Fujiwara, H. Yamana, T. Fujii, K. Kawamoto, T. Sasaki and H. Moriyama, "Solubility of Uranium(IV) Hydrous Oxide in High pH Solution under Reducing Condition," Radiochimica Acta, Vol. 93, No. 6, 2005, pp. 347350. doi:10.1524/ract.93.6.347.65643

[25] T. Sasaki, S. Kubo, T. Kubota, I. Takagi and H. Moriyama, "Complex Formation of Lanthanides(III) and Actinides(III) with Dicarboxylates Containing Soft Donor Groups," Journal of Alloys and Compounds, Vol. 408412, 2006, pp. 1283-1286. doi:10.1016/j.jallcom.2005.04.130

[26] C. F. Baes and R. E. Mesmer, "The Hydrolysis of Cations," John Wiley \& Sons, New York, 1976.

[27] J. Du, N. Sato and O. Tochiyama, "Potentiometric Study on the Proton Binding of Humic Substances," Journal of Nuclear and Radiochemical Sciences, Vol. 6, No. 1, 2005, pp. 25-29.

[28] O. Tochiyama, Y. Nibbori, K. Tanaka, H. Yoshino, T. Kubota, A. Kirishima and B. Setiawan, "Modeling of the Complex Formation of Metal Ions with Humic Acids," Radiochimica Acta, Vol. 92, No. 9-11, 2004, pp. 559-565. doi:10.1524/ract.92.9.559.54996

[29] K. Müller and T. Sasaki, "Complex Formation of Np(V) with Fulvic Acid at Tracer Metal Concentration," Radiochimica Acta, 2012, in press.

[30] T. Sasaki, T. Kobayashi, I. Takagi and H. Moriyama, "Discrete Fragment Model for Complex Formation of Europium(III) with Humic Acid," Journal of Nuclear Science and Technology, Vol. 45, No. 8, 2008, pp. 718724. doi: $10.3327 /$ jnst. 45.718

[31] W. Hummel, M. A. Glaus and L. R. Van Loon, "Trace Metal-Humate Interactions. II. The 'Conservative Roof' Model and Its Application," Applied Geochemistry, Vol. 15, 2000, pp. 975-1001. doi:10.1016/S0883-2927(99)00100-6 